\title{
Effect of Molecular Weight of Polyethylene Glycol on Copper Electrodeposition in the Presence of Bis-3-Sulfopropyl-Disulfide
}

\author{
Sol-Ji Song ${ }^{1}$, Seok-Ryul Choi ${ }^{1}$, Jung-Gu Kim ${ }^{1, *}$, Ho-Gun Kim ${ }^{2}$ \\ ${ }^{1}$ School of Advanced Materials Science and Engineering, Sungkyunkwan University, 300 Chunchun- \\ Dong, Jangan-Gu, Suwon 440-746, Republic of Korea \\ ${ }^{2}$ LG R\&D Copmlex, 555, Hogye-Dong, Dongan-Gu, Anyang 431-080, Republic of Korea \\ *E-mail: kimjg@skku.edu
}

doi: $10.20964 / 2016.12 .45$

Received: 20 June 2016 / Accepted: 11 August 2016 / Published: 10 November 2016

\begin{abstract}
This study examined the effect of polyethylene glycol (PEG) with different molecular weights on the copper electrodeposition in acid copper sulfate plating solution containing bis-3-sulfopropyl-disulfide (SPS) and chloride ion. Quantum chemical study, cyclic voltammetry, and surface analyses (HP-thin film XRD, FE-SEM) were conducted to evaluate the adsorption nature, crystallographic characteristics, and surface morphology. In copper electrodeposition, the adsorption effect of PEG is dependent on its molecular weight regardless of the existence of SPS. The increase of suppression effect with high PEG molecular weight induced the SPS biasing action which causes the change of surface property such as roughness, glossiness, preferred plane and grain size. In addition, PEG activated SPS reactions.
\end{abstract}

Keywords: copper electrodeposition, polyethylene glycol, 3-sulfopropyl-disulfide, adsorption, surface property

\section{$\underline{\text { FULL TEXT }}$}

(C) 2016 The Authors. Published by ESG (www.electrochemsci.org). This article is an open access article distributed under the terms and conditions of the Creative Commons Attribution license (http://creativecommons.org/licenses/by/4.0/). 